\title{
Control of AGC in Interconnected Power System with Diverse Sources of Power Generation
}

\author{
Majid Alizadeh Moghadam*, Saeed Jalilzadeh \\ Electrical Engineering Department, University of Zanjan, Zanjan, Iran \\ *Corresponding Author: alizadeh@znu.ac.ir
}

Copyright () 2014Horizon Research Publishing All rights reserved

\begin{abstract}
In this paper, automatic generation control (AGC) of two area interconnected power system having diverse sources of power generation is studied. A two area power system comprises power generations from hydro, thermal and gas sources in area-1 and power generations from hydro and thermal sources in area-2. All the power generation units from different sources are equipped with speed governors. A continuous time transfer function model of the system for studying dynamic response for small load disturbances is presented. A proportional-integral-derivative (PID) automatic generation control scheme is applied only to power generations from thermal and gas sources and power generation from hydro source is allowed to operate at its scheduled level with only speed governor control. The two area power system is simulated for different nominal loading conditions. Particle Swarm Optimization (PSO) is used to obtain the optimal PID gains for various cases using integral squared error plus integral time absolute error (ISE+ITAE) performance index for fitness evaluation. Some of the transient responses are shown for different nominal loading conditions due to step load disturbances in the system.
\end{abstract}

Keywords Two Area Power System, Diverse Sources of Power Generation, Automatic Generation Control, Particle Swarm Optimization, PID Controller 2

\section{Introduction}

Power systems consist of control areas representing a coherent group of generators i.e. generators which swing in unison characterized by equal frequency deviations. In addition to their own generations and to eliminate mismatch between generation and demand these control areas are interconnected through tie-lines for providing contractual exchange of power under normal operating conditions. One of the control problems in power system operation is to maintain the frequency and power interchange between the areas at their rated values. Automatic generation control is to provide control signals to regulate the real power output of various electric generators within a prescribed area in response to changes in system frequency and tie-line loading so as to maintain the scheduled system frequency and established interchange with other areas (Elgerd, 1971). The performance of the automatic generation control depends upon how various power generating units respond to these signals. The speed of their response is limited by natural time lags of the various turbine dynamics and the power system itself. In other words the design of automatic generation controller depends upon various energy source dynamics involved in the AGC of the area. A large number of research papers have been published in the last three decades in which the power system considered for these studies were two area thermal-thermal or hydro-thermal systems (Abdel-Magid et al. 1995; Elgerd et al. 1970; Karnavas 2006; Wang, 1993). But in real situations each control area may have large number of various sources of power generation such as hydro, thermal, gas, nuclear etc. The various generations are connected by a stiff network that is why the frequency deviations are assumed to be equal in an area.

The load over a day varies which is evident from a daily load curve. Therefore the contributions of generations from various sources in an area are adjusted to meet the load variations. The performance of the Automatic Generation Control may also vary in respect to the changes in the share of different type of power generations to the total generation of the area. In order to obtain the optimum realistic AGC performance, the automatic generation controller parameters have to be optimized for various nominal loading conditions. In practice, it is not necessary that all type of power generating units having speed governors may take part in the area AGC activity. Due to the lower power production cost a typical generation in an area may be contributing to its maximum by running at its rated load capacity while others may not be. In such case the typical generation is regulated by the speed governor alone but its dynamics will also play a role in the selection of the automatic generation controller parameters for other generations in the area. The authors have studied the automatic generation control of single area power system with diverse sources of power generation (Ramakrishna et al., 2007). It has been shown that the dynamics of all the energy sources in the area are required to be incorporated for obtaining the optimum controller 
parameters. It has also been shown that the dynamic performance of the system is better if each individual source have an optimum automatic generation controller than a common controller for all sources in an area.

In order to obtain better transient performance of the system various control strategies have been applied to the automatic generation control problem (Abdel-Magid et al. 1995, El-Saady et al. 2002, Karnavas 2006, Olmos et al. 2004). The optimum response can only be achieved with proper tuning of various controller parameters subjected to minimization of different performances indices. Tuning of conventional proportional and integral gains by using different performance indices have been studied in (Abdel-Magid 1995, Karnavas 2006). It has been observed that ISE criterion weighs heavily on the large fluctuation as compared to the small one. Therefore, it is more effective in reducing the initial swings of the transient response. The ITAE criterion is more suitable in reducing long duration transients as it penalizes the error by time. In this paper selection of PID controller gains using a combination of ISE and ITAE (Ramakrishna et al., 2007) criterion is presented for automatic generation control of two area interconnected power system with diverse sources of power generation.
Particle Swarm Optimization (PSO) algorithm is used to optimize the controller parameters for different nominal loading conditions. The PSO algorithms are a stochastic global search method that mimics the process of natural evolution. Due to its high potential for global optimization, PSO has received great attention in control systems such as the search of optimal PID controller parameters.

\section{Power System Model}

Figure 1 represents the detailed transfer function block diagram of an area with diverse sources of electric power generation namely, thermal, hydro and gas. The uncontrolled two area power system as shown in Figure 2 has power generations from hydro, thermal and gas sources in area-1 and from hydro and thermal sources in area-2.

The thermal, hydro and gas based power generating units are represented by respective single plant dynamics (Elgerd, 1971, Hajagos et al. 2001, Lalor et al. 2005, Kundur 1970). Under normal operating conditions there is no mismatch between generation and load. The total generations in area-1 and area -2 are given by :

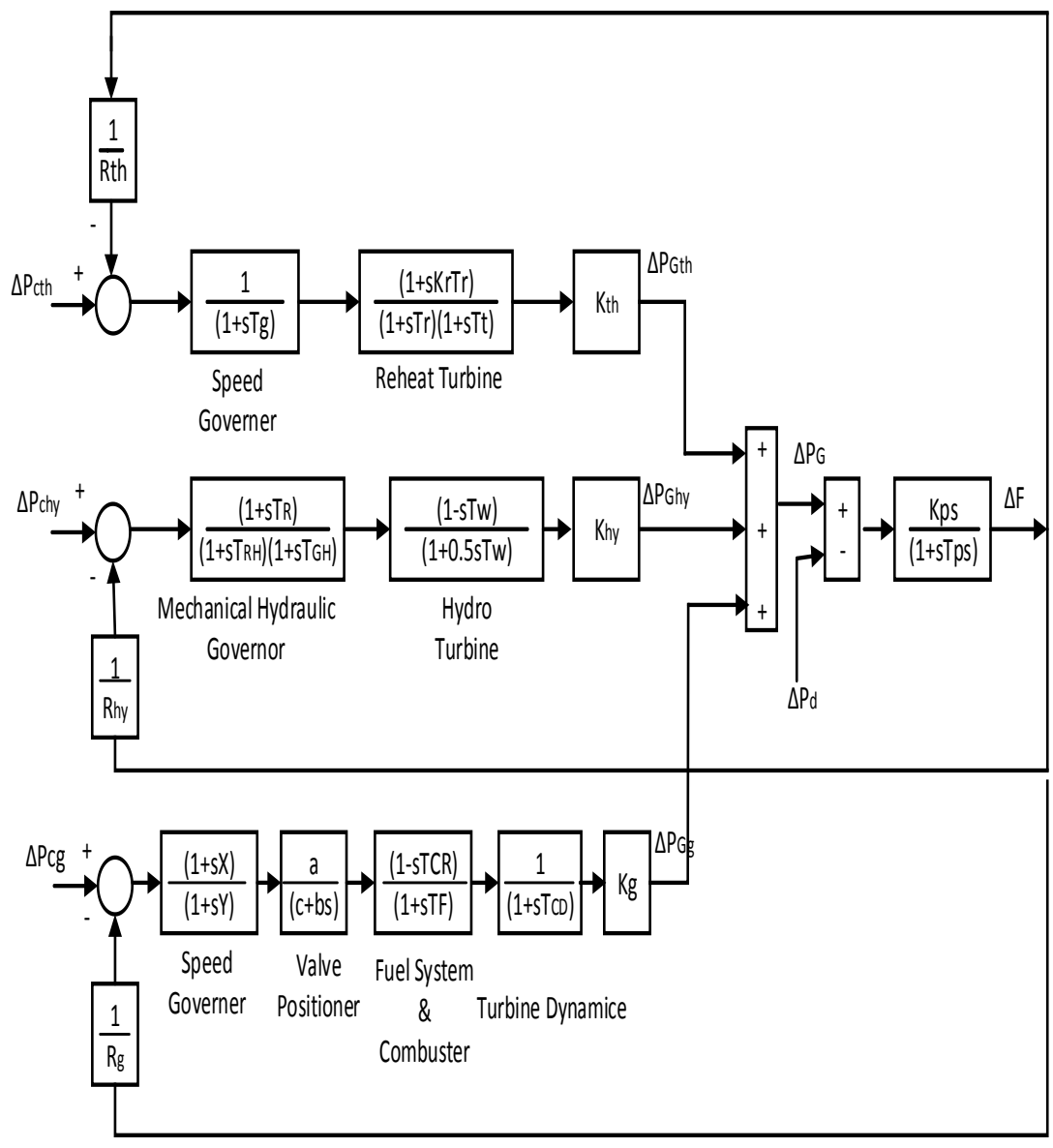

Figure 1. Transfer Function Block Diagram of an Area having Power Generations from Hydro, Thermal and Gas Sources 


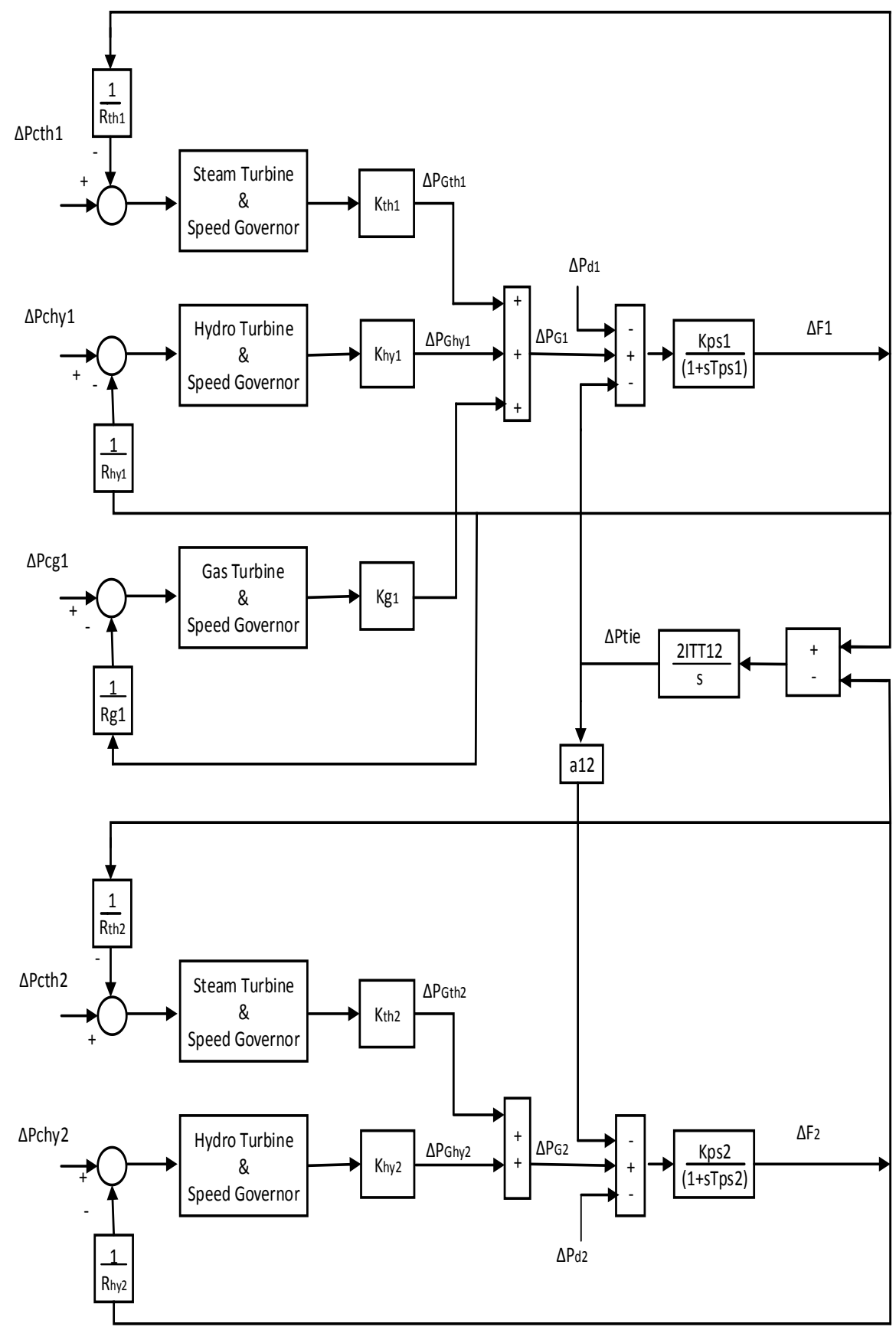

Figure 2. Block Diagram of a Two Area Power System 


$$
\begin{gathered}
P_{G 1}=P_{G t h 1}+P_{G h y 1}+P_{G g 1} \\
P_{G 2}=P_{G t h 2}+P_{G h y 2}
\end{gathered}
$$

Where

$$
P_{G t h i}=K_{t h i} P_{G i}, \quad P_{G h y i}=K_{h y i} P_{G i}, \mathrm{i}=1,2
$$

And

$$
P_{G 1}=K_{g 1} P_{G 1}
$$

$\mathrm{K}_{\mathrm{th}}, \mathrm{K}_{\mathrm{hy}}$ and $\mathrm{K}_{\mathrm{g}}$ represent the share of the power generation by thermal, hydro and gas sources respectively to the total power generation. The values of $K_{t h}, K_{h y}$ and $K_{g}$ depend upon the total load and also involve economic load dispatch. For small perturbation (1) and (2) can be written as:

$$
\begin{gathered}
\Delta P_{G 1}=\Delta P_{G t h 1}+\Delta P_{G h y 1}+\Delta P_{G g 1} \\
\Delta P 2=\Delta P_{G t h 2}+\Delta P_{G h y 2}
\end{gathered}
$$

From (1) and (2) under nominal generation and loading, $\mathrm{P}_{\mathrm{G}}{ }^{0}=\mathrm{P}_{\mathrm{L}}^{0}=1.0 \mathrm{pu}$, we have

$$
\begin{gathered}
K_{G t h 1}+K_{G h y 1}+K_{g 1}=1 \\
K_{G t h 2}+K_{G h y 2}=1
\end{gathered}
$$

The uncontrolled two area power system shown in Figure 2 becomes controlled system by having manipulations of the speed changer signals. It is assumed that only thermal and gas power generating units act in the automatic generation control of the system by having manipulations of $\Delta \mathrm{P}_{\mathrm{Cth}}$, $\Delta \mathrm{P}_{\mathrm{Cth} 2}$ and $\Delta \mathrm{P}_{\mathrm{Cg} 1}$. The hydro generating unit in both areas is uncontrolled, i.e. $\Delta \mathrm{P}_{\text {Chyi }}=0(\mathrm{i}=1,2)$. The speed changer signals are given by:

$$
\begin{gathered}
\Delta P_{C t h i}=K_{P t h i} A C E_{i}+ \\
K_{I t h i} \int A C E_{i} d t+K_{D t h i} \frac{d}{d t}\left(A C E_{i}\right) \\
\Delta P_{C g 1}=K_{P g 1} A C E_{1}+ \\
K_{I g 1} \int A C E_{1} d t+K_{D g 1} \frac{d}{d t}\left(A C E_{1}\right) \\
A C E_{i}=B \Delta f_{i}+\Delta P_{T i e}
\end{gathered}
$$

The dynamic performance of the system depends upon these proportional, integral and derivative gains.

\section{Parameter Optimization}

The PSO algorithm is an evolutionary computation technique introduced by Kennedy and Eberhart in 1995. The underlying motivation for the development of PSO was social behavior of animals such as bird flocking. The PSO algorithm is similar to Genetic Algorithm (GA) in that the system is initialized with a population of random solutions.
However, in PSO, each individual of the population, called particle, has an adaptable velocity, according to the search space which it moves over. In this problem PSO is used to optimize the gains of conventional PID controller with (ISE+ITAE) performance index as fitness functions. The performance indices are given by:

$$
\begin{gathered}
I S E=\Delta P_{\text {tie }}^{2}+\Delta f_{1}^{2}+\Delta f_{2}^{2} \\
I T A E=t\left(\left|\Delta P_{\text {tie }}\right|+\left|\Delta f_{1}\right|+\left|\Delta f_{2}\right|\right) \\
\eta_{I S E+I T A E}=\int(I S E+I T A E) d t
\end{gathered}
$$

Each practical keeps track of its coordinate in hyperspace, which are associated with the solution (flatness value) it has achieved so far. This value is called $p_{\text {best }}$ Another "best" value is called $g_{\text {best }}$ that is obtained so far by any particle in the population and stored the overall best value.

In the basic version of the PSO algorithm each particle in the population manipulated according to the following assignment statements:

$$
\begin{gathered}
v_{i d}^{t}=w v_{i d}^{t-1}+c_{1} r_{1}\left(p_{i d}-x_{i d}^{t-1}\right)+c_{2} r_{2}\left(p_{g d}-x_{g d}^{t-1}\right) \\
x_{i d}^{t}=x_{i d}^{t-1}+v_{i d}^{t}
\end{gathered}
$$

Where $v_{i d}{ }^{t}$ and $x_{i d}{ }^{t}$ are the velocity and position of the $i^{t h}$ particle in the $t^{\text {th }}$ iteration, $\mathrm{p}_{\mathrm{id}}$ is the best position the $i^{\text {th }}$ particle has accomplished at the $(t-1)^{t h}$ iteration, and $p_{g d}$ is the global best position achieved in the particle at the $(t-1)^{t h}$ iteration. $\mathrm{C} 1$ and $\mathrm{C} 2$ are two positive constants called acceleration constants. $\mathrm{r} 1$ and $\mathrm{r} 2$ are two different random numbers in the range of 0 to 1 . The maximum velocity $v_{\max }$ determines the maximum change one particle can take during iteration, and determines the precision between current position and the global best position. If $v_{\max }$ is large value, the particle may fly beyond the best solution; if $v_{\max }$ is small value, particle cannot precede enough searches outside the partial good zone and sinks into the local optimized value. Usually we set the range of the particle as $v_{\max }$ and unified maximum velocity can also be set up, and can set the each dimension maximum velocity $v_{\max }$ according to dimension. The inertia weight $w$ keeps the movement inertial for the particle. It describes influence of the previous velocity to the current velocity, which means make the algorithm have the trend to extend the search space and have the ability to explore the new district, and there is the function to adjust the rate of velocity of particle. The inertia weight is decreased linearly from 0.9 to 0.4 . Linear variety of the $w$ :

$$
W=W_{\max }-\left(\frac{W_{\max }-W_{\min }}{G_{\max }}\right)
$$

Where: $w_{\max }$ is the maximum inertia weight, usually $w_{\max }=0.9 ; w_{\min }$ is the minimum inertia weight, usually $w_{\min }=0.4 ; G_{\max }$ is the maximum number of iteration; $\mathrm{G}$ is the current number of iteration. 


\section{Simulation Studies}

A typical example of two area power system is considered for the simulation and the values of the different parameters of the system are given in Appendix-I. The initial values of the performance indices were obtained by carrying simulation of the system over a period of $100 \mathrm{sec}$ with automatic generation controller gain parameters obtained from randomly selected initial population. These values were used to produce next generation of individuals and procedure is repeated until the population has converged to some minimum value of the performance index. The parameters for PSO process are given in Appendix-II. The two area system with diverse sources of power generation is simulated for different cases with $1 \%$ step load perturbation in either of the areas. The scheduled generations from each of the sources for different nominal loading conditions for both areas are given in Table T1 in Appendix-I. The transient responses of the system are given below for optimum values of PID gains which are evaluated using ISE+ITAE criterion. Finally, complete content and organizational editing before formatting. Please take note of the following items when proofreading spelling and grammar:

\subsection{Case I: $1 \%$ Step Load Disturbance in Area 1}

The two area system is simulated for various operating conditions for $1 \%$ step load disturbance only in area 1

Table 1. Optimal PID Controller Gain Value For Different Thermal Power Generation in Area-1 to Match Nominal Loading Conditions With 1\% Step Load Disturbance in Area-1

\begin{tabular}{|c|c|c|c|c|c|c|}
\hline \multicolumn{7}{|c|}{ Area 1} \\
\hline \multirow{2}{*}{ Load } & \multicolumn{3}{|c|}{ Thermal } & \multicolumn{3}{|c|}{ Gas } \\
\hline & $\mathrm{K}_{\text {Pth1 }}$ & $\mathrm{K}_{\mathrm{Ith} 1}$ & $\mathrm{~K}_{\text {Dth1 }}$ & $\mathrm{K}_{\mathrm{Pg} 1}$ & $\mathrm{~K}_{\mathrm{Ig} 1}$ & $\mathrm{~K}_{\mathrm{Dg} 1}$ \\
\hline 1750 & 59.4706 & 305.8798 & 16.0235 & 0.2900 & 0.6870 & 0.0426 \\
\hline 1500 & 75.8446 & 300.0647 & 24.0190 & 0.4444 & 0.6870 & 0.0237 \\
\hline 1250 & 57.6227 & 387.5332 & 14.4084 & 0.2934 & 0.6870 & 0.0169 \\
\hline 1000 & 120.6009 & 343.2426 & 27.6336 & 0.4863 & 0.0687 & 0.0424 \\
\hline \multicolumn{7}{|c|}{ Area 2} \\
\hline \multirow{2}{*}{ Load } & \multicolumn{6}{|c|}{ Thermal } \\
\hline & \multicolumn{2}{|c|}{$\mathrm{K}_{\text {Pth2 }}$} & \multicolumn{2}{|c|}{$\mathrm{K}_{\mathrm{Ith} 2}$} & \multicolumn{2}{|c|}{$\mathrm{K}_{\mathrm{Dth} 2}$} \\
\hline 1750 & \multicolumn{2}{|c|}{41.8750} & \multicolumn{2}{|c|}{0.5857} & \multicolumn{2}{|c|}{2.1052} \\
\hline 1750 & \multicolumn{2}{|c|}{27.2266} & \multicolumn{2}{|c|}{0.3941} & \multicolumn{2}{|c|}{2.2499} \\
\hline 1750 & \multicolumn{2}{|c|}{21.6102} & \multicolumn{2}{|c|}{0.7897} & \multicolumn{2}{|c|}{3.5739} \\
\hline 1750 & \multicolumn{2}{|c|}{0.0424} & \multicolumn{2}{|c|}{0.5287} & \multicolumn{2}{|c|}{0.1013} \\
\hline
\end{tabular}

\subsubsection{Different Scheduled Thermal Power Generation in Area1}

The optimal values of the PID controller gains are given in Table 1 for different thermal power generations in area-1 to match the system nominal loading conditions. The other scheduled generations are kept constant. It has been observed that the optimal values of $\mathrm{K}_{\mathrm{Pth} 1}, \mathrm{~K}_{\mathrm{Ith} 1}, \mathrm{~K}_{\mathrm{Dth} 1,} \mathrm{~K}_{\mathrm{Ig} 1}$ and $\mathrm{K}_{\mathrm{Ith2}}$ are increasing and $\mathrm{K}_{\mathrm{Dth} 2}$ is decreasing with decrease in thermal power generation. The transient system responses are shown in Figure 3. It has been observed that as the scheduled thermal generation is reduced to match the reduced nominal loading, system shows poor transient response with increase in first peak deviation.

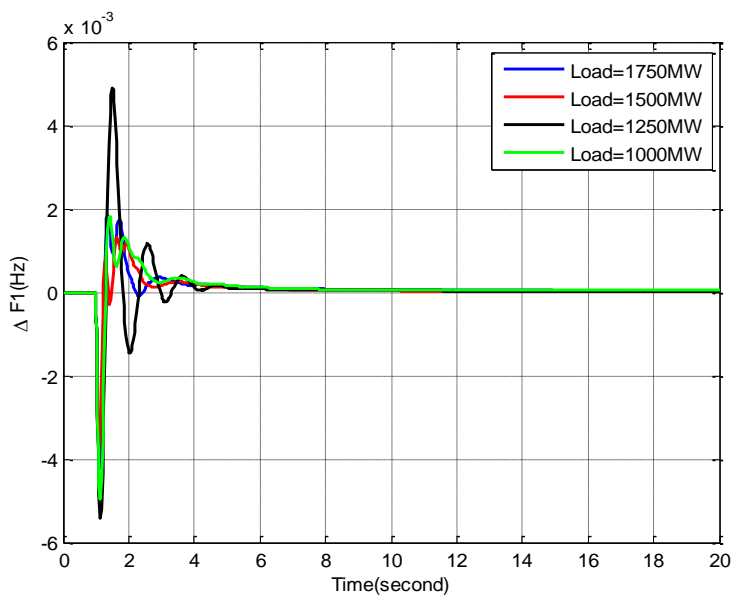

(a) Area-1 Frequency Deviation

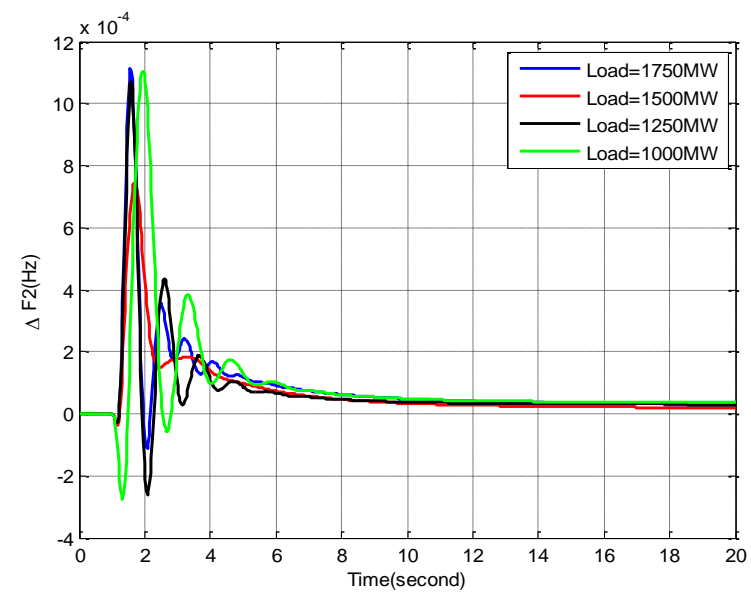

(b) Area-2 Frequency Deviation

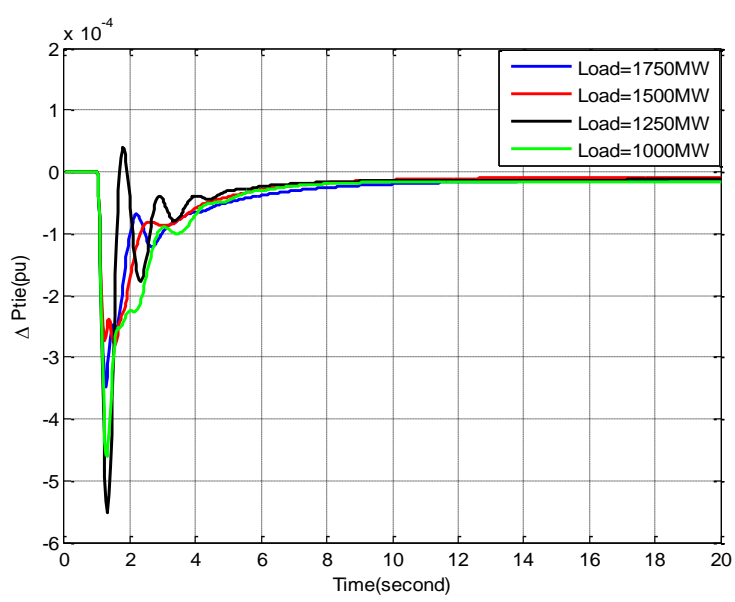

(c) Tie-Line Power Deviation

Figure 3. System transient responses for different thermal power generations of area-1with $1 \%$ step load disturbance in area-1

\subsubsection{Different Scheduled Gas Power Generation in Area 1}


The optimal values of PID controller gains are given in Table 2 for different gas power generations in area- 1 to match the system nominal loading conditions and keeping other scheduled power generations constant. It has been observed that the optimal values of $\mathrm{K}_{\mathrm{Pth} 1}, \mathrm{~K}_{\mathrm{Ith} 1}, \mathrm{~K}_{\mathrm{Dth} 1}, \mathrm{~K}_{\mathrm{Pth} 2}$ and $K_{\mathrm{Dth} 2}$ are decreasing and $\mathrm{K}_{\mathrm{Pg} 1}$ and $\mathrm{K}_{\mathrm{Ig} 1}$ are increasing with decrease in scheduled load. As the scheduled gas power generation is reduced to match the reduced nominal loading, the system transient response deteriorates by increasing the first peak as shown in Figure 4.

Table 2. Optimal PID Controller Gain Value For Different Gas Power Generation in Area-1 to Match Nominal Loading Conditions With 1\% Step Load Disturbance in Area-1

\begin{tabular}{|c|c|c|c|c|c|c|}
\hline \multicolumn{7}{|c|}{ Area 1} \\
\hline \multirow{2}{*}{ Load } & \multicolumn{3}{|c|}{ Thermal } & \multicolumn{3}{|c|}{ Gas } \\
\hline & $\mathrm{K}_{\mathrm{Pth} 1}$ & $\mathrm{~K}_{\text {Ith1 }}$ & $K_{\text {Dth1 }}$ & $K_{\mathrm{Pg} 1}$ & $\mathrm{~K}_{\mathrm{Ig} 1}$ & $K_{\text {Dg1 }}$ \\
\hline 1750 & 84.4310 & 300.8798 & 21.9417 & 0.1945 & 0.6870 & 0.0320 \\
\hline 1650 & 28.0530 & 76.8226 & 5.4374 & 0.2747 & 0.6877 & 0.0264 \\
\hline 1550 & 144.0706 & 97.5812 & 26.1000 & 0.2531 & 0.6196 & 0.0269 \\
\hline \multicolumn{7}{|c|}{ Area 2} \\
\hline \multirow{2}{*}{ Load } & \multicolumn{6}{|c|}{ Thermal } \\
\hline & \multicolumn{2}{|c|}{$\mathrm{K}_{\mathrm{Pth} 2}$} & \multicolumn{2}{|c|}{$\mathrm{K}_{\mathrm{Ith} 2}$} & \multicolumn{2}{|c|}{$\mathrm{K}_{\text {Dth2 }}$} \\
\hline 1750 & \multicolumn{2}{|c|}{24.7002} & \multicolumn{2}{|c|}{70.5583} & \multicolumn{2}{|c|}{4.0749} \\
\hline 1750 & \multicolumn{2}{|c|}{23.8412} & \multicolumn{2}{|c|}{0.8146} & \multicolumn{2}{|c|}{3.503} \\
\hline 1750 & \multicolumn{2}{|c|}{1.5294} & \multicolumn{2}{|c|}{0.3673} & \multicolumn{2}{|c|}{17.0759} \\
\hline
\end{tabular}

\subsubsection{Different Scheduled Gas Power Generation in Area 1}

The optimal values of PID controller gains are given in Table 3 for different thermal power generations in area- 2 to match the system nominal loading conditions. The other scheduled power generations are kept constant. The optimal values of $\mathrm{K}_{\mathrm{Ith} 1}, \mathrm{~K}_{\mathrm{Pg} 1}, \mathrm{~K}_{\mathrm{Ig} 1}$ and $\mathrm{K}_{\mathrm{Dth} 2}$ are increasingand $\mathrm{K}_{\mathrm{Dth} 1}$, $\mathrm{K}_{\mathrm{Pth} 2}$ andK $\mathrm{K}_{\mathrm{Ith} 2}$ aredecreasing with decrease in scheduled thermal power generation. The transient system responses are shown in Figure5. Again it has been observed that the system shows poor transient response with increase in first peak deviation as thermal power generation is reduced.

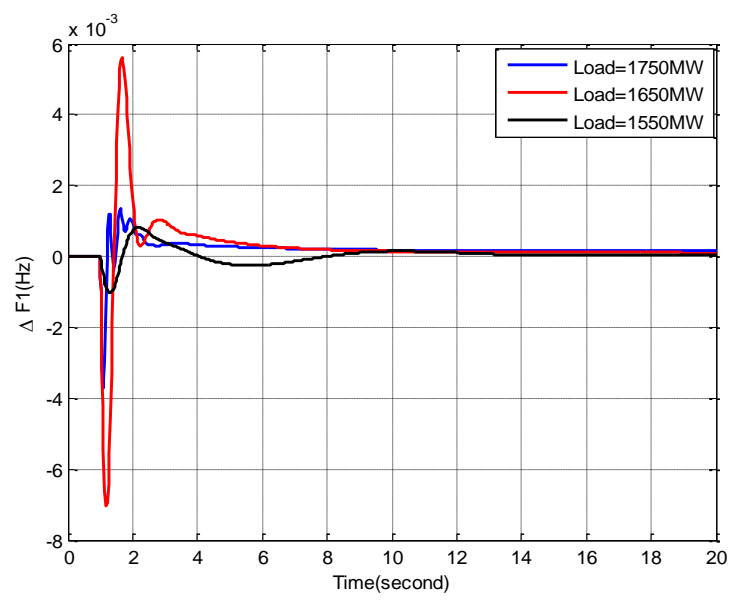

(a) Area-1 Frequency Deviation

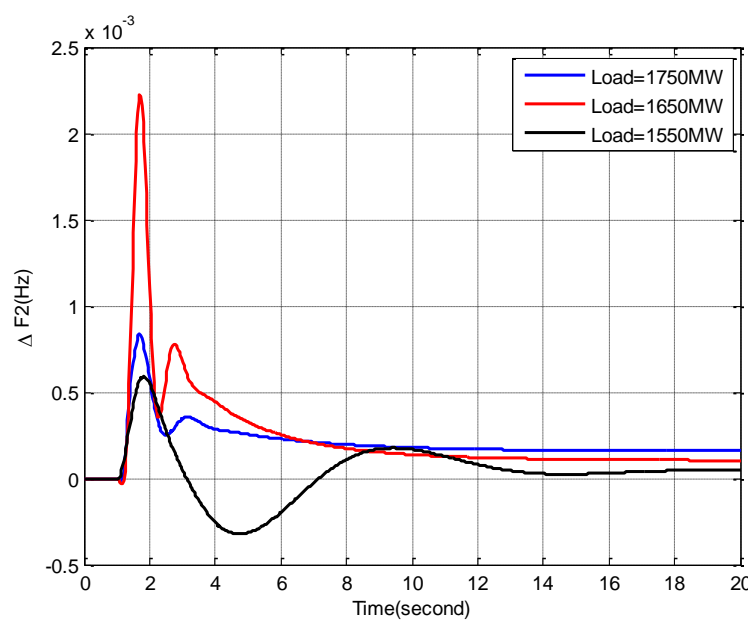

(b) Area-2 frequency deviation

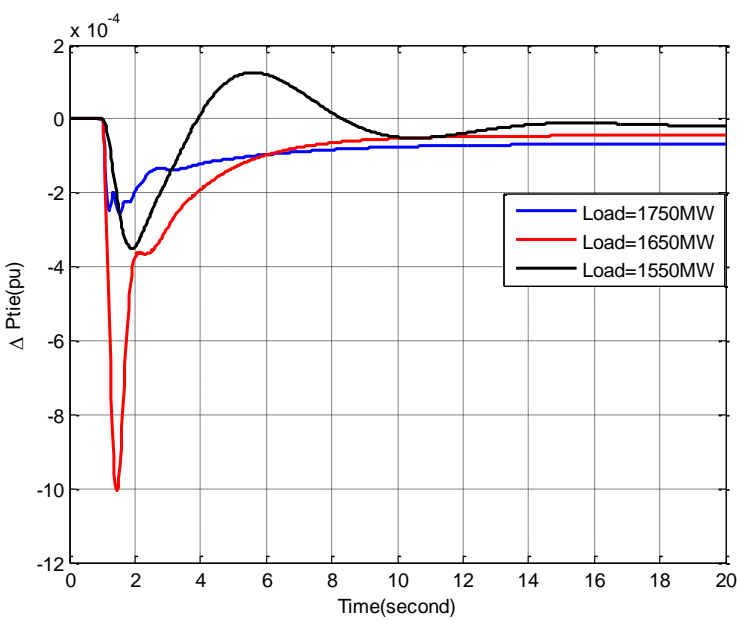

(c) tie-line power deviation

Figure 4. System Transient Responses for Different Gas Power Generations of Area-1 with $1 \%$ Step Load Disturbance in area-1

Table 3. Optimal PID Controller Gain Value For Different Thermal Power Generation in Area-2 to Match Nominal Loading Conditions With 1\% Step Load Disturbance in Area-1

\begin{tabular}{|c|c|c|c|c|c|c|}
\hline \multicolumn{7}{|c|}{ Area 1} \\
\hline \multirow{2}{*}{ Load } & \multicolumn{3}{|c|}{ Thermal } & \multicolumn{3}{|c|}{ Gas } \\
\hline & $\mathrm{K}_{\text {Pth1 }}$ & $\mathrm{K}_{\text {Ith1 }}$ & $\mathrm{K}_{\text {Dth1 }}$ & $\mathrm{K}_{\mathrm{Pg} 1}$ & $\mathrm{~K}_{\mathrm{Ig} 1}$ & $\mathrm{~K}_{\text {Dg1 }}$ \\
\hline 1750 & 47.4706 & 343.8798 & 30.0859 & 1.4822 & 0.6671 & 0.0120 \\
\hline 1500 & 60.0666 & 343.8815 & 29.5661 & 0.4813 & 0.6870 & 0.0158 \\
\hline 1250 & 67.4812 & 273.3483 & 28.3783 & 0.05588 & 0.6870 & 0.0245 \\
\hline 1000 & 69.9210 & 243.1788 & 11.9565 & 0.1810 & 0.6870 & 0.0300 \\
\hline \multicolumn{7}{|c|}{ Area 2} \\
\hline \multirow{2}{*}{ Load } & \multicolumn{6}{|c|}{ Thermal } \\
\hline & \multicolumn{2}{|c|}{$K_{\text {Pth2 }}$} & \multicolumn{2}{|c|}{$\mathrm{K}_{\text {Ith2 }}$} & \multicolumn{2}{|c|}{$\mathrm{K}_{\text {Dth2 }}$} \\
\hline 1750 & \multicolumn{2}{|c|}{1.9500} & \multicolumn{2}{|c|}{0.2583} & \multicolumn{2}{|c|}{12.0392} \\
\hline 1750 & \multicolumn{2}{|c|}{3.9500} & \multicolumn{2}{|c|}{0.1988} & \multicolumn{2}{|c|}{11.1124} \\
\hline 1750 & \multicolumn{2}{|c|}{33.4708} & \multicolumn{2}{|c|}{0.2101} & \multicolumn{2}{|c|}{3.3159} \\
\hline 1750 & \multicolumn{2}{|c|}{36.1837} & \multicolumn{2}{|c|}{0.1117} & \multicolumn{2}{|c|}{1.9998} \\
\hline
\end{tabular}




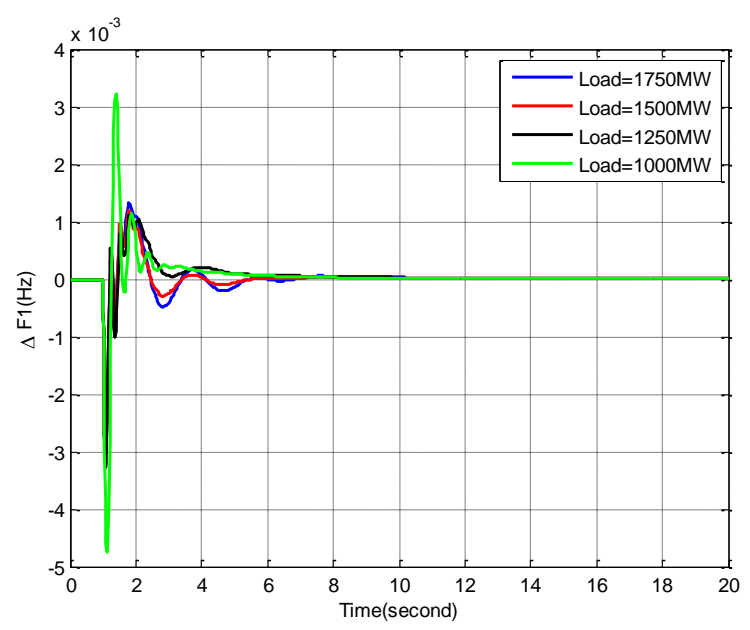

(a) Area-1 Frequency Deviation

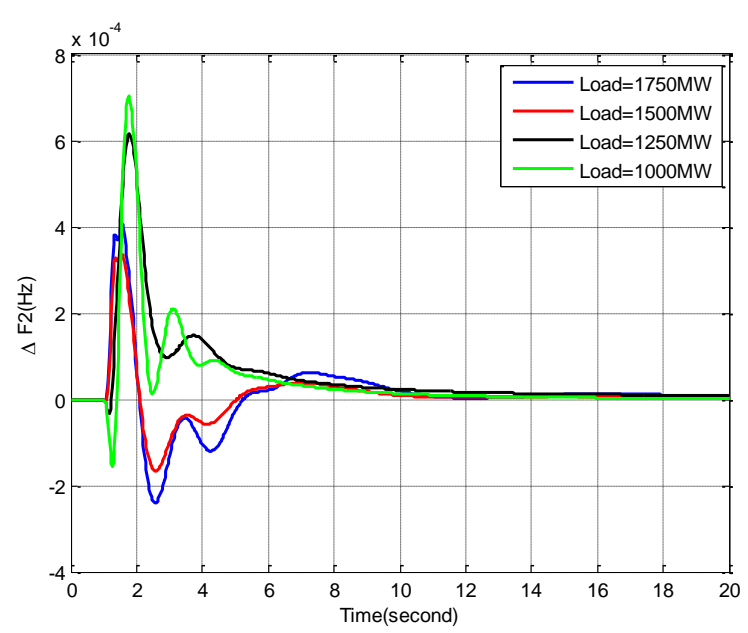

(b) Area-2 Frequency Deviation

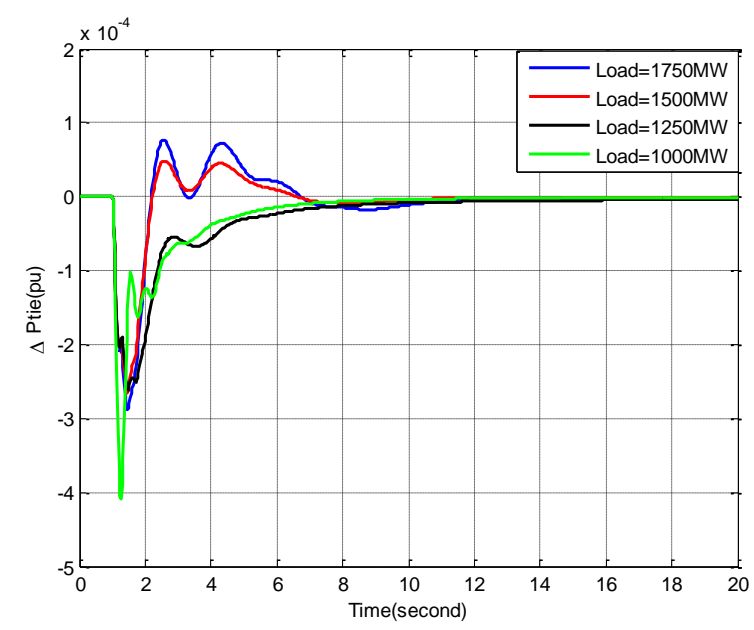

(c)tie-line Power Deviation

Figure 5. System Transient Responses for Different Thermal Power Generations of area-1with $1 \%$ Step Load Disturbance in area-1

\subsection{Case I: $1 \%$ Step Load Disturbance in Area 2}

The two area power system is simulated for various operating conditions for $1 \%$ step load disturbance in area-2.

\subsubsection{Different Scheduled Thermal Power Generation in Area1}

The optimal values of the PID controller gains are given in Table 4 for different thermal power generations in area- 1 to match the system nominal loading conditions. The other scheduled generations are kept constant. It has been observed that with decrease in scheduled thermal power generation the optimal values of $\mathrm{K}_{\text {Pth1, }} \mathrm{K}_{\text {Ith1 }}, \mathrm{K}_{\text {Dth1, }} \mathrm{K}_{\text {Pth2, }} \mathrm{K}_{\text {Ith2 }}$ and $\mathrm{K}_{\mathrm{Dth} 2}$ are increasing asnominalload decreases. The transient system responses are shown in Figure 6. It has been observed that the system transient response improves with decrease in first peak deviation as scheduled thermal power generation is reduced to match the normal operating load.

Table 4. Optimal PID Controller Gain Value For Different Thermal Power Generation in Area-1 to Match Nominal Loading Conditions With $1 \%$ Step Load Disturbance in Area-2

\begin{tabular}{|c|c|c|c|c|c|c|}
\hline \multicolumn{7}{|c|}{ Area 1} \\
\hline \multirow{2}{*}{ Load } & \multicolumn{3}{|c|}{ Thermal } & \multicolumn{3}{|c|}{ Gas } \\
\hline & $\mathrm{K}_{\mathrm{Pth} 1}$ & $\mathrm{~K}_{\mathrm{Ith} 1}$ & $\mathrm{~K}_{\text {Dth1 }}$ & $\mathrm{K}_{\mathrm{Pg} 1}$ & $\mathrm{~K}_{\mathrm{Ig} 1}$ & $\mathrm{~K}_{\mathrm{Dg} 1}$ \\
\hline 1750 & 60.2941 & 343.6395 & 10.1431 & 0.0968 & 9.6870 & 0.0878 \\
\hline 1500 & 64.9833 & 333.519 & 10.1432 & 0.0155 & 0.6887 & 0.0679 \\
\hline 1250 & 65.5686 & 445.467 & 30.1941 & 0.0841 & 0.632 & 0.0688 \\
\hline 1000 & 67.1961 & 543.106 & 33.8431 & 0.0101 & 1.1600 & 0.0001 \\
\hline \multicolumn{7}{|c|}{ Area 2} \\
\hline \multirow{2}{*}{ Load } & \multicolumn{6}{|c|}{ Thermal } \\
\hline & \multicolumn{2}{|c|}{$\mathrm{K}_{\mathrm{Pth} 2}$} & \multicolumn{2}{|c|}{$\mathrm{K}_{\text {Ith2 }}$} & \multicolumn{2}{|c|}{$\mathrm{K}_{\text {Dth2 }}$} \\
\hline 1750 & \multicolumn{2}{|c|}{51.9240} & \multicolumn{2}{|c|}{390.3781} & \multicolumn{2}{|c|}{8.0945} \\
\hline 1750 & \multicolumn{2}{|c|}{52.9240} & \multicolumn{2}{|c|}{390.1714} & \multicolumn{2}{|c|}{9.0927} \\
\hline 1750 & \multicolumn{2}{|c|}{52.431} & \multicolumn{2}{|c|}{357.4703} & \multicolumn{2}{|c|}{9.05068} \\
\hline 1750 & \multicolumn{2}{|c|}{53.9240} & \multicolumn{2}{|c|}{397.4933} & \multicolumn{2}{|c|}{9.9651} \\
\hline
\end{tabular}

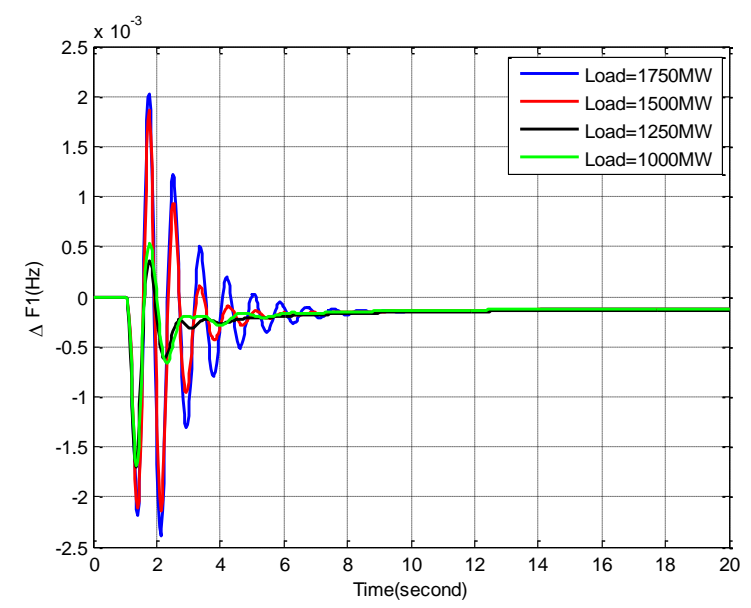

(a) Area-1 frequency deviation 


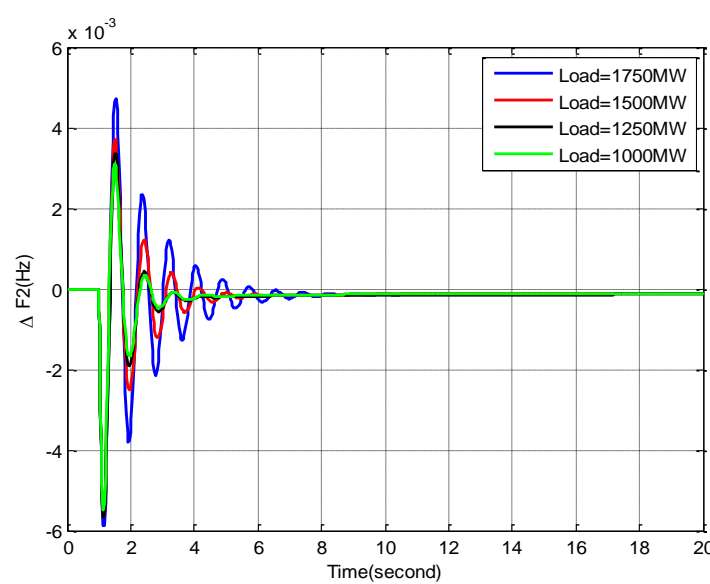

(b)Area-2 frequency deviation

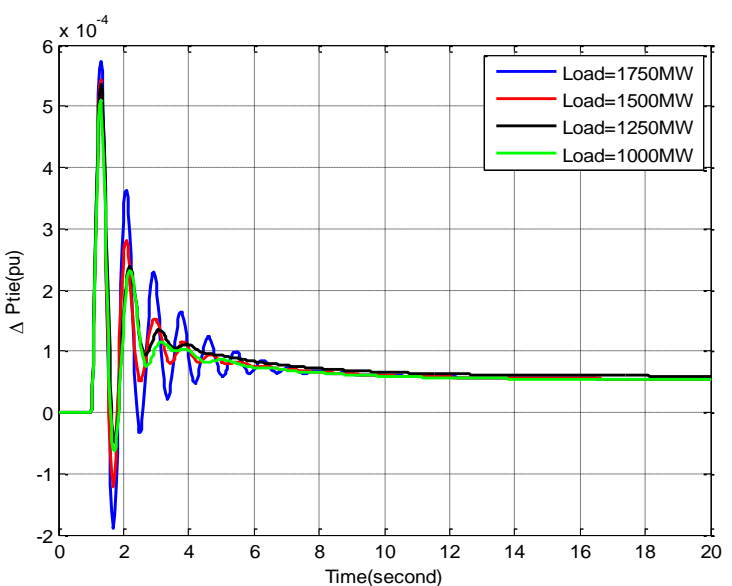

(c)tie-line power deviation

Figure6. System Transient Responses for Different Thermal Power Generations of area-1with 1\% Step Load Disturbance in area-2

Table 5. Optimal PID Controller Gain Value For Different Gas Power Generation in Area-1 to Match Nominal Loading Conditions With 1\% Step Load Disturbance in Area-2

\begin{tabular}{|c|c|c|c|c|c|c|}
\hline \multicolumn{7}{|c|}{ Area 1} \\
\hline \multirow{2}{*}{ Load } & \multicolumn{3}{|c|}{ Thermal } & \multicolumn{3}{|c|}{ Gas } \\
\hline & $\mathrm{K}_{\text {Pth1 }}$ & $\mathrm{K}_{\text {Ith1 } 1}$ & $\mathrm{~K}_{\text {Dth1 }}$ & $\mathrm{K}_{\mathrm{Pg} 1}$ & $\mathrm{~K}_{\mathrm{Ig} 1}$ & $\mathrm{~K}_{\mathrm{Dg} 1}$ \\
\hline 1750 & 70.2941 & 410.0837 & 10.8001 & 0.0168 & 0.8672 & 0.0667 \\
\hline 1650 & 75.1069 & 554.139 & 11.1235 & 0.0477 & 0.6198 & 0.0013 \\
\hline 1550 & 60.0003 & 592.7090 & 10.6051 & 0.0201 & 0.7662 & 0.0687 \\
\hline \multicolumn{7}{|c|}{ Area 2} \\
\hline \multirow{2}{*}{ Load } & \multicolumn{6}{|c|}{ Thermal } \\
\hline & \multicolumn{2}{|c|}{$\mathrm{K}_{\mathrm{Pth2}}$} & \multicolumn{2}{|c|}{$\mathrm{K}_{\text {Ith2 }}$} & \multicolumn{2}{|c|}{$\mathrm{K}_{\mathrm{Dth} 2}$} \\
\hline 1750 & \multicolumn{2}{|c|}{43.9224} & \multicolumn{2}{|c|}{314.0781} & \multicolumn{2}{|c|}{10.0945} \\
\hline 1750 & \multicolumn{2}{|c|}{41.9240} & \multicolumn{2}{|c|}{317.1004} & \multicolumn{2}{|c|}{15.0955} \\
\hline 1750 & \multicolumn{2}{|c|}{40.9588} & \multicolumn{2}{|c|}{300.0502} & \multicolumn{2}{|c|}{30.0988} \\
\hline
\end{tabular}

\subsubsection{Different Scheduled Gas Power Generation in Area-1}

The optimal values of PID controller gains are given in Table 5 for different gas power generations in area-1 to match the system nominal loading conditions and keeping other scheduled power generations constant. It has been observed that the optimal gains $\mathrm{K}_{\mathrm{Pth} 1} \mathrm{~K}_{\mathrm{Dth} 1}, \mathrm{~K}_{\mathrm{Ith} 2}$ and $\mathrm{K}_{\mathrm{Dth} 2}$ are increasing with decrease in nominal loading. The transient system responses are shown in Figure 7. It has been found that the decrease in gas power generation the system shows better transient response.

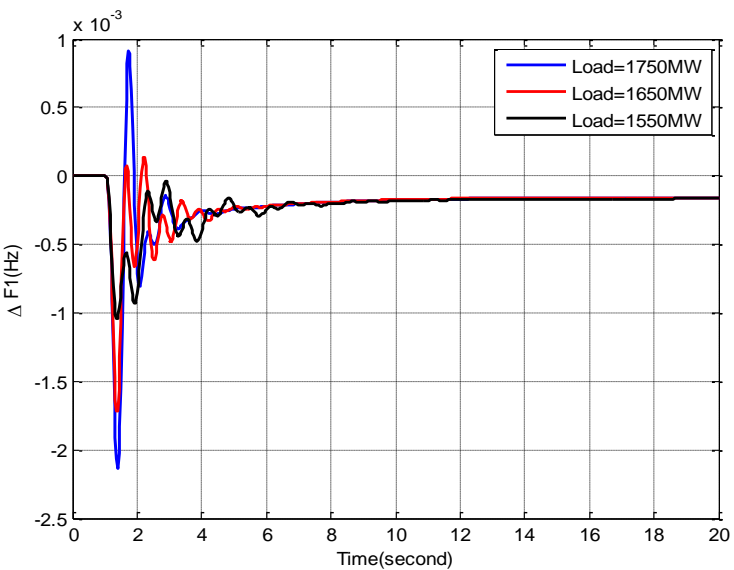

(a) Area-1 frequency deviation

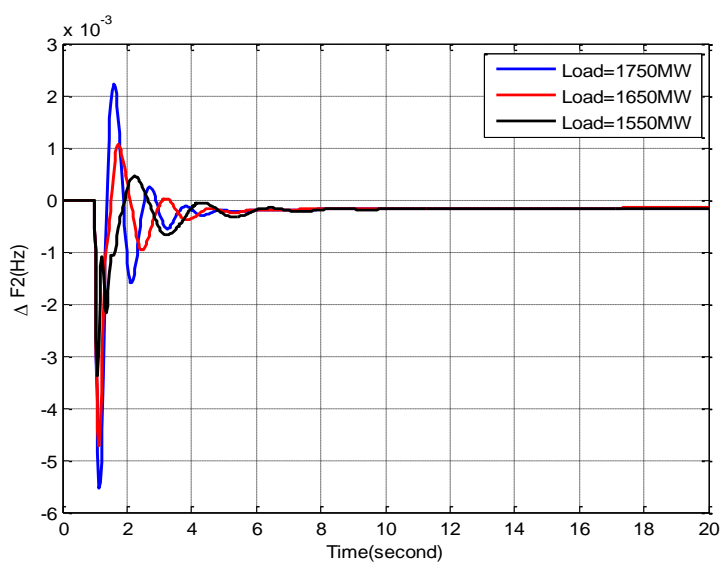

(b) Area-2 frequency deviation

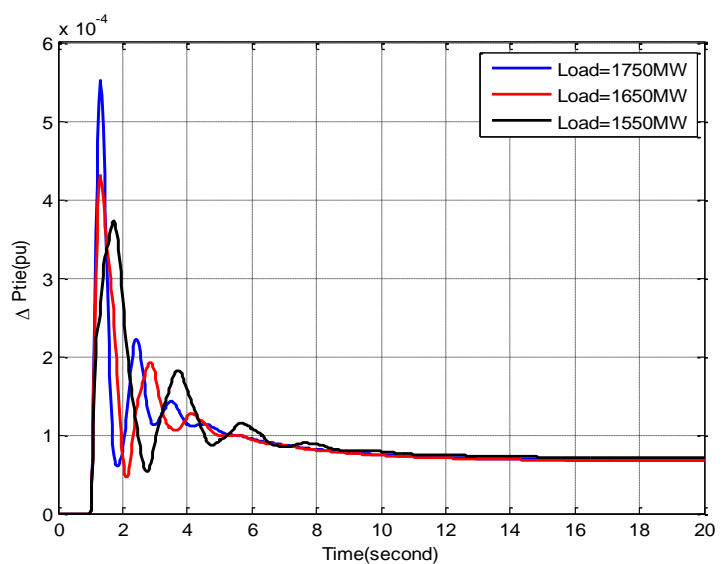

(c) tie-line power deviation

Figure 7. System Transient Responses for Different Gas Power Generations of area-1with 1\% Step Load Disturbance in area-2

\subsubsection{Different Scheduled Thermal Power Generation in Area2}

The optimal values of the PID controller gains are given 
Table 6 for different scheduled thermal power generation in area-2. It has been observed that the optimal gains $\mathrm{K}_{\mathrm{Pth} 1}$ and $\mathrm{K}_{\mathrm{Dth} 1}$ are decreasing but $\mathrm{K}_{\mathrm{Pth} 2}$ and $\mathrm{K}_{\mathrm{Ith} 2}$ are increasing as thermal power generation is reduced to match the nominal loading. The transient responses of the system are shown in Figure 8. It has been observed that the system transient responses deteriorate with decrease in the thermal power generation.

Table 6. Optimal PID Controller Gain Value For Different Thermal Power Generation in Area-1 to Match Nominal Loading Conditions With $1 \%$ Step Load Disturbance in Area-2

\begin{tabular}{|c|c|c|c|c|c|c|}
\hline \multicolumn{7}{|c|}{ Area 1} \\
\hline \multirow{2}{*}{ Load } & \multicolumn{3}{|c|}{ Thermal } & \multicolumn{3}{|c|}{ Gas } \\
\hline & $\mathrm{K}_{\text {Pth1 }}$ & $\mathrm{K}_{\text {Ith1 }}$ & $\mathrm{K}_{\text {Dth1 }}$ & $\mathrm{K}_{\mathrm{Pg} 1}$ & $\mathrm{~K}_{\mathrm{Ig} 1}$ & $K_{\mathrm{Dg} 1}$ \\
\hline 1750 & 60.2941 & 343.6395 & 10.1431 & 0.0968 & 9.6870 & 0.0878 \\
\hline 1500 & 64.9833 & 333.519 & 10.1432 & 0.0155 & 0.6887 & 0.0679 \\
\hline 1250 & 65.5686 & 445.467 & 30.1941 & 0.0841 & 0.632 & 0.0688 \\
\hline 1000 & 67.1961 & 543.106 & 33.8431 & 0.0101 & 1.1600 & 0.0001 \\
\hline \multicolumn{7}{|c|}{ Area 2} \\
\hline \multirow{2}{*}{ Load } & \multicolumn{6}{|c|}{ Thermal } \\
\hline & \multicolumn{2}{|c|}{$\mathrm{K}_{\mathrm{Pth} 2}$} & \multicolumn{2}{|c|}{$\mathrm{K}_{\text {Ith2 }}$} & \multicolumn{2}{|c|}{$\mathrm{K}_{\text {Dth2 }}$} \\
\hline 1750 & \multicolumn{2}{|c|}{51.9240} & \multicolumn{2}{|c|}{390.3781} & \multicolumn{2}{|c|}{8.0945} \\
\hline 1750 & \multicolumn{2}{|c|}{52.9240} & \multicolumn{2}{|c|}{390.1714} & \multicolumn{2}{|c|}{9.0927} \\
\hline 1750 & \multicolumn{2}{|c|}{52.431} & \multicolumn{2}{|c|}{357.4703} & \multicolumn{2}{|c|}{9.05068} \\
\hline 1750 & \multicolumn{2}{|c|}{53.9240} & \multicolumn{2}{|c|}{397.4933} & \multicolumn{2}{|c|}{9.9651} \\
\hline
\end{tabular}

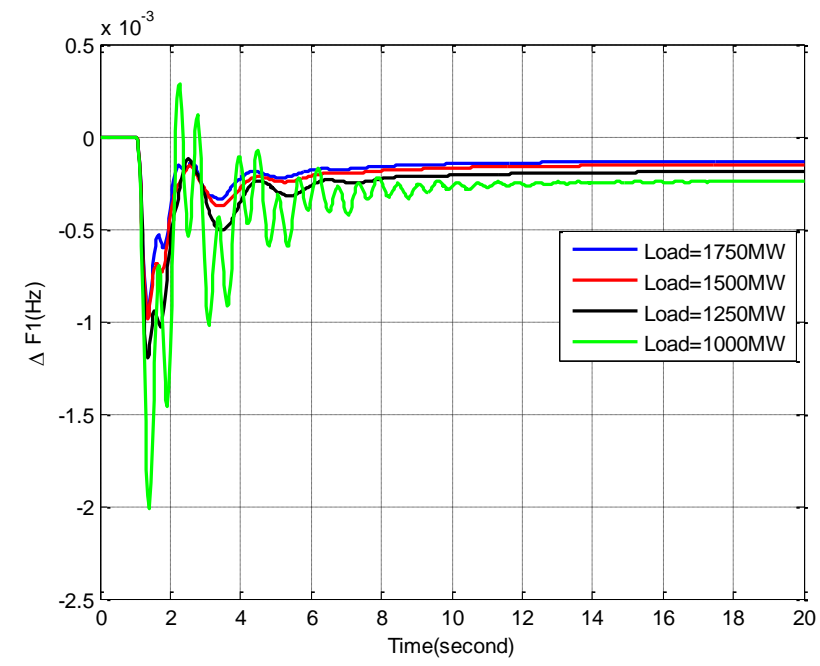

(a) Area-1 frequency deviation

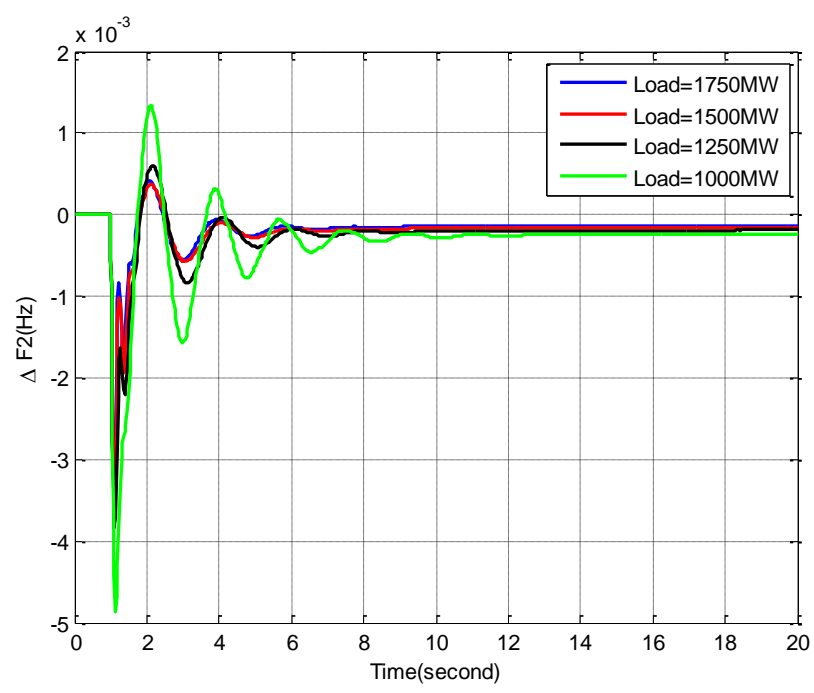

(b) Area-2 frequency deviation

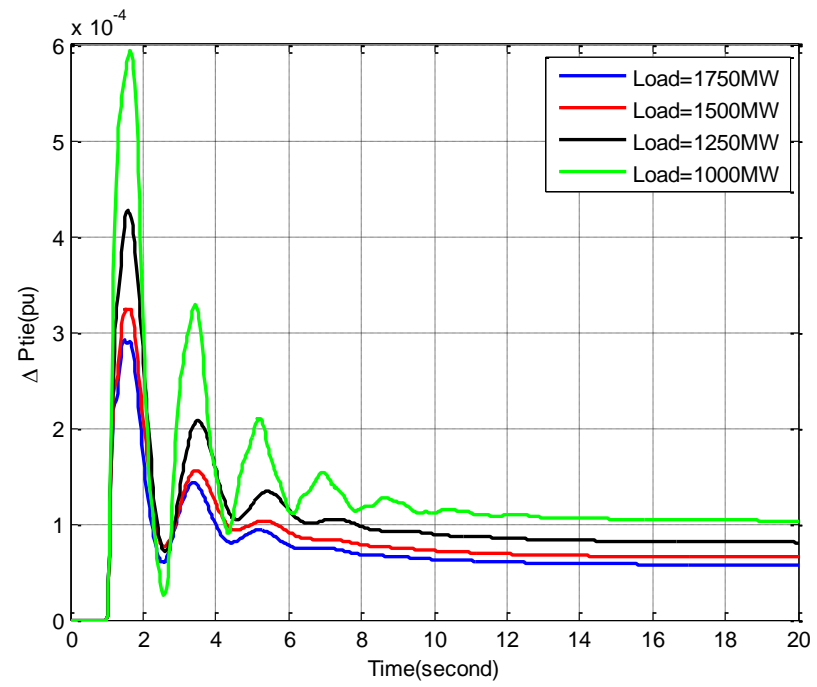

(c) tie-line power deviation

Figure 8. System transient responses for different thermal power generations of area-1with $1 \%$ step load disturbance in area-2 


\section{Conclusions}

AGC of a two area power system having power generation from hydro, thermal and gas sources in area-1 and from hydro and thermal in area-2 has been studied. The typical two area system has been simulated for different scheduled generations under different normal loading conditions with $1 \%$ step load disturbance in either area. The scheduled power generations from thermal or gas are adjusted to match the system normal operating load. The PID controller gains have been optimized using genetic algorithm for various cases. It has been found that the optimal gains of the AGC are different for different loading conditions. Also to achieve better dynamic performance, the gains have been found to be different for each source in an area. Therefore the selection of AGC gains based on one typical nominal loading of the system and also by considering one source of power generation in area is not a realistic study. Hence in realistic power system having diverse sources of power generation, the dynamics of all energy sources must be incorporated for automatic generation controller design.

\section{Appendix-I}

System Data:

The data of a typical two area power system having diverse sources of power generation are given below.

Steam Turbine:

Speed governor time constant $\mathrm{T}_{\mathrm{g}}=0.08 \mathrm{sec}$

Turbine time constant $\mathrm{T}_{\mathrm{t}}=0.3 \mathrm{sec}$

Re-heater time constant $\mathrm{T}_{\mathrm{r}}=10 \mathrm{sec}$

Coefficient of re-heat steam turbine $\mathrm{K}_{\mathrm{r}}=0.3$

Speed governor regulation parameter $\mathrm{R}_{\mathrm{th}}=2.4 \mathrm{~Hz} / \mathrm{pu} \mathrm{MW}$

Hydro turbine:

Speed governor rest time $T_{R}=5.0 \mathrm{sec}$

Transient droop time constant $\mathrm{T}_{\mathrm{RH}}=28.75 \mathrm{sec}$

Main servo time constant $\mathrm{T}_{\mathrm{GH}}=0.2 \mathrm{sec}$

Water time constant $\mathrm{T}_{\mathrm{W}}=1.0 \mathrm{sec}$

Speed governor regulation parameter $\mathrm{R}_{\mathrm{hy}}=2.4 \mathrm{~Hz} / \mathrm{pu} \mathrm{MW}$

Gas Turbine:

Speed governor lead and lag time constants $\mathrm{X}=0.6 \mathrm{sec}$ and

$\mathrm{Y}=1.0 \mathrm{sec}$ Valve positioner constants $\mathrm{a}=1, \mathrm{~b}=0.05$ and $\mathrm{c}=1$

Fuel time constant $\mathrm{T}_{\mathrm{F}}=0.23 \mathrm{sec}$

Combustion reaction time delay $\mathrm{T}_{\mathrm{CR}}=0.3 \mathrm{sec}$

Compressor discharge volume time constant $T_{C D}=0.2 \mathrm{sec}$

Speed governor regulation parameter $\mathrm{R}_{\mathrm{g}}=2.4 \mathrm{~Hz} / \mathrm{pu} \mathrm{MW}$

Power System:

Rated area capacity $\mathrm{P}_{\mathrm{r} 1}=\mathrm{P}_{\mathrm{r} 2}=2000 \mathrm{MW}$

Inertia constant $\mathrm{H}=5 \mathrm{MW}$-s/MVA

Rated frequency $\mathrm{f}_{\mathrm{r}}=60 \mathrm{~Hz}$

Frequency bias constant $B_{1}=B_{2}=0.425 \mathrm{puMW} / \mathrm{Hz}$

Tie-Line: $\mathrm{P}_{12 \max }=100 \mathrm{MW} \quad\left(\delta_{1}-\delta_{2}\right)=30$

Load Frequency Characteristic $\quad D=\frac{\partial P_{L}}{\partial f} \frac{1}{P_{r}} \mathrm{pu} \mathrm{MW/Hz}$
Power System Gain Constant

$K_{P S}=\frac{1}{D} \quad \mathrm{~Hz} / \mathrm{pu} \mathrm{Mw}$

Power System Time Constant $\quad T_{P s}=\frac{2 H}{f_{r} D} \quad$ sec

\section{REFERENCES}

[1] K. S. S. Ramakrishna,Pawan Sharma, T. S. Bhatti‘Automatic generation control of interconnected power system with diverse sources of power generation' International Journal of Engineering, Science and Technology Vol. 2, No. 5, 2010, pp. $51-65$

[2] Abdel-Magid Y. L. and Dawoud, M. M. 1995. Tuning of interconnected reheat thermal systems with genetic algorithms, IEEE International Conference on Systems, Man and Cybernetics, Vol. 3, pp. 2622-2627.

[3] Cam E and Ilhan, K. 2005. Automatic generation control in two area power systems using fuzzy logic controller, Energy Conversion Management, Vol. 46, No. 2, pp. 233-243.

[4] Cavin R. K., Budge M. C., Rasmussen P. 1971. An optimal linear systems approach to load-frequency control, IEEE Trans. Power App. and Syst; PAS-90, pp. 2472-2482.

[5] Choi S. S. and. Sim, H. K 1981. Automatic generation control via constrained limited-feedback, Electrical Power Systems Research, Vol. 4, No. 4, pp. 265-269. 0

[6] Chown G. A. and Hartman R. C. 1998. Design and experience with a fuzzy logic controller for automatic generation control, IEEE Trans. Power Sys., Vol. 13, No. 3, pp. 965-970.

[7] Doolla S. and Bhatti, T.S. 2006. Automatic generation control of an isolated small-hydro power plant with reduced dump load, IEEE Trans. Power Syste., Vol. 21, No. 4, pp. 1912-1919.

[8] El-Saady G., Yousef A. M. and. El- M. K. Sherbiny 2002. Efficient fuzzy logic automatic generation controller, Energy Conversion Management, Vol. 43, No. 14, pp. 1853-1863.

[9] Elgerd O. I. 1971. Electrical Energy systems theory: An Introduction, 2nd ed., Tata McGraw Hill..

[10] Elgerd O. I., Fosha C. E., 1970. Optimum megawatt-frequency control of diverse-area electric energy systems, IEEE Trans. Power App. and Syst., PAS-89, pp. 556-563.

[11] Hajagos L. M and Berube G. R. 2001.Utility experience with gas turbine testing and modeling, IEEE Power Engineering Society Winter Meeting. Conference Proc., Vol. 2, No. 2, pp. 671-677.

[12] Karnavas Y. L., 2006. On the optimal automatic generation control of an interconnected hydro electric power systems using genetic algorithms, Proceedings of the 6th IASTED International Conference on European Power and Energy Systems, Cd Ref. No 521-099.

[13] Kundur, P. 1993. Power system stability and control. McGraw-Hill. New Delhi. 
[14] Lalor, G. Mullane A., O’Malley M. 2005. Frequency control and wind turbine technologies, IEEE Trans. Power Syst. Vol.4, pp. 1905-1913.

[15] Malik, O. P. Kumar A., Hope, G. S. 1988. Automatic generation control algorithm based on a generalized approach, IEEE Trans. Power Syst.,Vol.3, No.2,pp. 378-382.

[16] Miniesy S. M., Bohn, E. V. 1972. Optimum load frequency continuous control with unknown deterministic power demand, IEEE Trans Power App and Syst., PAS-91, pp. 1910-1915.

[17] Olmos L., de la Fuente J. I.,. Macho J. L. Z,.Pecharroman R. R, Calmarza A. M., Moreno, J. 2004. New design for the Spanis scheme using an adaptive gain controller, IEEE Trans. Power Syst., Vol. 19, No. 3, pp. 1528-1537.

[18] Ramakrishna K.S.S. and Bhatti, T.S. 2007. Sampled-data automatic generation control of a single area power system with multi-source power generation. Electric Power Components and Systems, Vol. 35, No.8, pp. 966-981

[19] Rerkpreedapong D., Hasanovic A., A. Feliachi, 2003. Robust automatic generation control using genetic algorithms and linear matrix inequalities, IEEE Trans. Power Syst., Vol. 18, No. 2, pp. 855-861.

[20] Tripathy, S.C. Bhatti T.S., Jha, C.S. Malik O.P.,. Hope G. S. 1984. Sampled data automatic generation control analysis with reheat steam turbines and governor dead band effects, IEEE Trans. Power App. Syst; PAS-103, pp.1045-1051.
[21] Tripathy S. C.,.Mital N, Bhatti T. S. 1983. Decentralized sub-optimal automatic generation control of hydro thermal power system using state variable model. Journal of the Institution of Engineers (India) Electrical Engineering Division, Vol. 64 (EL1), pp. 69-74.

[22] Talaq J. and Al-Basri, F. 1999. Adaptive fuzzy gain scheduling for automatic generation control, IEEE Trans. Power Syst., Vol. 14, No.1, pp.145-150.

[23] Wang, Y., Zhou, R., and Wen, C. 1993. Robust automatic generation controller design for power systems, Proceedings of the IEE-C, Vol. 140, No.1, pp. 111-116.

[24] Yamashita K. and Taniguchi T. 1986. Optimal observer design for automatic generation control, Electrical Power Systems Research, Vol. 8, No. 2, pp. 93-100.

[25] Yesil, E. GuzelkayaM.andEskins, I 2004. Self tuning fuzzy PID type automatic generation controller, Energy Conversion Management, Vol. 45, No. 3, pp.377-390.

[26] ShufangSuna, JiahaiZhanga, JianhuiWangb,LinXub.' The Application of New Adaptive PSO in AGC and AFC Combination Control System' (C) 2010 Published by Elsevier Ltd. Selection and/or peer-review under responsibility of Society for Automobile, Power and Energy Engineering, Procedia Engineering 16 ( 2011 ) 702-707. 